\title{
Effect of egg size and strain on growth performance of cockerel
}

\author{
${ }^{1}$ Egbeyale, L. T., S. S. Abiola ${ }^{1}$, O. M. Sogunle ${ }^{1}$ and M. O. Ozoje ${ }^{2}$ \\ ${ }^{1}$ Department of Animal Production and Health, University of Agriculture, P.M.B. 2240, \\ Abeokuta, Nigeria. \\ ${ }^{2}$ Department of Animal Breeding and Genetics, University of Agriculture, P.M.B. 2240, \\ Abeokuta, Nigeria.
}

\begin{abstract}
This study was conducted to determine the effect of egg size and strain on growth performance of cockerel chicks obtained from Dominant Black (DB) and Yaffa Brown (YB) strains of pullet. A total number of two hundred and seventy day-old cockerels hatched from three different egg sizes (i.e 45 chicks from small, medium and large egg sizes for each of DB and YB) were used for this study. Data obtained were subjected to analysis of variance in a $2 \times 3$ factorial experimental layout. The initial weight of the chicks was significantly $(P<0.05)$ influenced by the egg size. Final weight and average daily weight gain were the only growth parameters affected $(P<0.05)$ by egg size till the end of starter phase. The effect of strain on all the growth parameters measured were not significantly $(P>0.05)$ different. At the growing phase, feed intake decreased significantly $(P<0.05)$ with increase in egg size. It was concluded that setting of medium and large egg sizes could only be beneficial if the target was to sell chicks of the two strains at the end of chick phase.
\end{abstract}

Keywords: egg size, cockerel, performance, pullet

\section{INTRODUCTION}

Egg weight and chick weight at hatching are positively related (Khurshid et al., 2003). The size of the embryo before and at hatching can be altered by the weight of the egg and the incubation environment (Wilson, 1991). The performance potentiality of the chicken depends, in part, on egg quality. Egg quality is an important parameter for embryogenesis as well as for 1-d-old chick quality and growth. In hatchery management, the judgement of the quality of a dayold chick is usually based on qualitative aspects, such as abnormalities and contamination. Thus, dayold chick quality when removed from the hatcher seems to be an all-or-none question. Improved quality of a broiler flock at slaughter age can only be realized with high quality day-old chicks as starting material. This ensures greater survivability and better growth potential during the first days or first week of life (Christensen, 2001). According to Deeming (1995), dayold chick quality can be related to several factors, such as incubator quality, incubation environment, and egg characteristics. The growth response of males to egg weight is greater than that of females (Joubert et al., 1981). The report of Tufft and Jesen (1991) revealed that the effect of the egg weight on body weight at market age is independent of the age of the breeders from which the eggs originated. The effect of breeder age seems to be largely associated with egg weight. Conversion of feed into body weight by growing broilers does not seem to be directly related to their egg weight of origin. A portion of the body weight advantage attributable to birds from heavy eggs may be related to their associated increased feed intake (Pinchasov, 1991). In general, many agree that it is preferable to have eggs of average weight to achieve good hatchability as far as chicken, turkey, ducks and ostriches are concerned (Brah et al., 1999; Gonzales et al., 1999). Due to paucity of information on posthatching performance of cockerel chicks, the present study is designed to determine the effect of egg size on post hatching performance and carcass characteristics of cockerels hatched from small, medium and large size Nigerian eggs of two strains of pullet.

\section{MATERIALS AND METHODS}

Experimental Site: The experiment was carried out on deep litter in the poultry unit of the Teaching and Research Farm, University of Agriculture, Abeokuta, Ogun State. The site falls within the rain forest vegetation zone of South-Western Nigeria on 
Agric. Biol. J. N. Am., 2011, 2(12): 1445-1453

latitude $7^{\circ} 13^{\prime} 49.46^{\prime \prime} \mathrm{N}$, longitude $3^{\circ} 26^{\prime} 11.98 " \mathrm{E}$ and altitude of 76 meters above sea level. The climate is humid with a mean annual rainfall of $1037 \mathrm{~mm}$. The annual mean temperature and humidity is $34.7^{\circ} \mathrm{C}$ and $82 \%$, respectively.

Experimental Birds and Management: $A$ total of eight hundred and ten (810) hatching eggs of different sizes from Dominant Black (DB) and Yaffa Brown (YB) strains of pullet (i.e. 405 eggs per strain) were bought from a reliable breeder farm in Ogun State. The eggs from each strain were weighed and arranged into three (3) groups i.e small $(41.09 \mathrm{~g}$ $50.97 \mathrm{~g})$, medium $(50.98 \mathrm{~g}-57.39 \mathrm{~g})$ and large $(57.40 \mathrm{~g}-69.64 \mathrm{~g})$. Each treatment group contained one hundred and thirty five (135) eggs which were sub-divided into three (3) replicates of forty (45) eggs each in a $2 \times 3$ factorial design. A total number of two hundred and seventy day-old cockerels hatched from the three different egg sizes; 45 chicks from DB small (DBS), DB medium (DBM), DB large (DBL), YB small (YBS), YB medium (YBM) and YB large (YBL) egg sizes were used for this study. The chicks were intensively managed and randomly arranged into three replicates per treatment. Each replicate consisted of fifteen chicks. Feed and water were given to the birds ad libitum. Chick mash was given to the chicks for the first eight weeks while growers mash was supplied to the sixteenth week (Table 1). The experiment lasted for sixteen (16) weeks. The cockerels were raised on a deep litter system. The litter materials used was wood shavings. The birds were vaccinated against new castle disease and medications were provided against both gram negative and gram positive bacteria using broad spectrum antibiotics.

Carcass Measurement: At the end of $16^{\text {th }}$ week, 6 birds per treatment were randomly selected, slaughtered, plucked and eviscerated. The live, bled, plucked and dressed weights were recorded. Also, cut-up parts (head, neck, wing, breast, thighs, drumstick, etc.), organs (heart, gizzard, liver, kidney and spleen) and offals (oesophagus, crop, small intestine, abdominal fat and caeca) were weighed as criteria for the measurement of carcass parameters (NRC, 1994). All weights were taken using sensitive scale (Acculation model 2001-Electric Digital scale) and expressed as percentage of the live weight.

Statistical Analysis: All data collected were subjected to two-way Analysis of Variance (ANOVA) in a $2 \times 3$ factorial experimental layout (SAS, 1999) while significantly $(\mathrm{P}<0.05)$ different means were compared using Duncan's Multiple Range Test in the same software.

\section{RESULTS}

The effect of egg size and strain on the performance of cockerel chicks is presented in Table 2. The egg size had significant $(\mathrm{P}<0.05)$ effect on the means of initial weight, final weight and daily weight gain. Small chicks $(33.95 \mathrm{~g})$ were hatched from small eggs while large chicks $(41.94 \mathrm{~g})$ hatched from large eggs. The chicks maintained their size categories up to the end of chick phase. The final weight values ranged from $517.68 \mathrm{~g}$ (small-sized eggs) to $610.19 \mathrm{~g}$ (large-sized eggs) while medium-sized eggs recorded $591.31 \mathrm{~g}$. Daily feed intake increased $(P>0.05)$ with increase in the weight of chicks. The effect of strain on the means of all the parameters measured were not significant $(P>0.05)$. However, DB had numerical higher values of initial weight, final weight, weight gain per day, daily feed intake and protein intake. The effect of interaction between egg size and strain on the growth performance of the cockerel chicks at the end of starter phase had significant $(P<0.05)$ differences on the initial, final and daily weight gain of the birds (Table 3). The final weight favoured DB medium, large and YB large sized egg while DB and YB small sized eggs recorded least values. The daily weight gain followed the same pattern with final weight of the chicks. At the end of growing phase, feed intake (g/day) and protein intake (g/day/bird) were significantly $(\mathrm{P}<0.05)$ influenced by the treatment (Table 3 ). The final weights of the birds from small, medium and large-sized eggs (1242.91, 1287.49 and $1338.33 \mathrm{~g}$, respectively) were statistically similar. The effect of strain on the growth parameters did not show any significant $(P<0.05)$ difference. It was observed that no mortality occurred in YB but DB recorded $4.28 \%$ mortality. The final weight obtained for DB was $1350.09 \mathrm{~g}$ while that of YB was $1229.07 \mathrm{~g}$. The effect of interaction between egg size and strain was significant $(P<0.05)$ only on daily feed intake and protein intake (Table 4). The highest value of feed intake (97.12 g/day) was recorded for DBS while the other treatments were statistically $(P<0.05) \quad$ comparable. Final weight ranged from $1150.00-1425.00 \mathrm{~g}$. The highest value $(1425.00 \mathrm{~g})$ was obtained from DBM while the least value $(1150.00 \mathrm{~g})$ was from YBM. The feed efficiency for both DBM and YBL (0.16) appeared to be best among all the treatments. The carcass parameters which were significantly $(P<0.05)$ influenced by the effect of egg size were lungs, bone and small intestine (Table 5). Cockerels from medium-sized 
eggs had the highest value $(0.69 \%)$ of lungs while birds from small and large-sized eggs were statistically similar and the values were 0.60 and $0.64 \%$, respectively. It was observed that birds from small-sized eggs had highest value (17.53\%) of bone while those from large eggs recorded the least value of $15.86 \%$. Though the live weights were not significant $(P>0.05)$, the values obtained resulted from the initial egg weight. The values of live weight for small, medium and large were 1191.67, 1229.17 and $1235.83 \mathrm{~g}$, respectively. The dressing percentage was in reverse order of the live weight and it ranged from $58.51-59.59 \%$. The value of small intestine length $(170.95 \mathrm{~cm})$ of birds from largesized eggs was highest $(P<0.05)$ while both small and medium-sized eggs were comparably (150.23 and $150.06 \mathrm{~cm}$, respectively) similar. The two parameters that were significantly $(P<0.05)$ affected by the effect of strain were the lung and the head. YB had higher values of lung and head $(0.69$ and $3.83 \%$ respectively) whereas DB recorded 0.60 and $3.40 \%$ respectively. Table 6 showed the effect of interaction between egg size and strain on the carcass characteristics of cockerels. The parameters significantly $(\mathrm{P}<0.05)$ affected include were hot dressed weight, lungs, head, wings, leg muscle and meat to bone ratio. Each group was favoured by different parameters. For instance, DBM recorded highest value of hot dressed weight, YBM had highest lungs, YBS for head and leg muscle, wings for DBS and meat to bone ratio for DBL and caecal weight for YBS. The means of dressing percentage ranged from 58.56 to $60.56 \%$ with DBM recording the highest value while the least value was from YBM. The highest mean value (2.22) of meat to bone ratio was obtained in DBL while the least value (1.81) was from DBS. The meat to bone ratio values of DBM, YBS, YBM and YBL were statistically comparable, the values were 1.97, 1.98, 2.00 and 1.94 respectively. The means of total muscle ranged from 31.12 - 34.78\% while bone was $15.69-17.79 \%$. Among the offals, small intestine length, large intestine weight, caecal weight and length were significantly $(P<0.05)$ influenced. The birds from YBL recorded longest small intestine length $(174.52 \mathrm{~cm})$ while the shortest length $(143.48 \mathrm{~cm})$ was from DBS. The small intestine length of birds from DBM, DBL, YBS and YBM were similar. The birds from DBS were favoured with large intestine weight, and caecal length when compared with their counterparts in other treatment groups.
Table 1: Composition (\%) of diets

\begin{tabular}{|c|c|c|}
\hline Ingredients & Chick mash & $\begin{array}{l}\text { Growers } \\
\text { mash }\end{array}$ \\
\hline Maize & 40.00 & 50.00 \\
\hline Fish meal & 2.00 & - \\
\hline Soybean meal & 18.00 & 12.00 \\
\hline Palm kernel cake & 10.00 & - \\
\hline Wheat offal & 25.00 & 33.00 \\
\hline Bone meal & 2.00 & 2.00 \\
\hline Oyster shell & 2.00 & 2.00 \\
\hline Lysine & 0.25 & 0.25 \\
\hline Methionine & 0.25 & 0.25 \\
\hline $\begin{array}{l}{ }^{*} \text { Chick's } \\
\text { vit/mineralpremix }\end{array}$ & 0.25 & - \\
\hline $\begin{array}{l}{ }^{\star *} \text { Grower's vit/mineral } \\
\text { premix }\end{array}$ & - & 0.25 \\
\hline Salt & 0.25 & 0.25 \\
\hline Total & 100.00 & 100.00 \\
\hline \multicolumn{3}{|l|}{$\begin{array}{l}\text { Calculated analysis } \\
(\%)\end{array}$} \\
\hline Crude protein & 18.71 & 15.09 \\
\hline Ether Extract & 5.09 & 4.95 \\
\hline Crude fibre & 4.56 & 4.22 \\
\hline Ash & 3.58 & 3.60 \\
\hline Calcium & 1.62 & 1.87 \\
\hline Phosphorus & 0.93 & 0.97 \\
\hline Lysine & 0.73 & 0.62 \\
\hline Methionine & 0.28 & 0.24 \\
\hline Energy (MJ/Kg) & 10.32 & 10.17 \\
\hline
\end{tabular}

30g; biotin, 0.05g; folic acid, 1.5g; choline chloride, 250g; nicotinic acid, 30g; Ca-Pantothenate, 15g; Co, 0.4g; Cu, 8g; Fe, 32g; I, 0.8g; Zn, 40g; Mn, 64g; Se, $0.16 \mathrm{~g}$, BHT, $5 \mathrm{~g}$.

${ }^{*}$ Vit./Min. Premix contained: Premix (Embavit No 90) contained Vit. A, 10 000 000iu; D3 , 2000 000iu ; E, 12 500iu; K, 1.30g; B1, 1.30; B2, 4.00g; D Calcium-Pantothenate, 1.30g; B6, 1.30g; B12, 0.01g; nicotinic acid, 15.00g; folic acid, 0.05g; biotin, 0.02g; Co, 0.20g; Cu, 5.00g; Fe, 25.00g; I, 0.06g; Mn, 48.00g; Se, 0.10g; Zn, 45.00g; choline chloride, 200.00g; BHT, 50.00g. 
AGRICULTURE AND BIOLOGY JOURNAL OF NORTH AMERICA

ISSN Print: 2151-7517, ISSN Online: 2151-7525, doi:10.5251/abjna.2011.2.12.1445.1453

(C) 2011, ScienceHuß, http://www.scihub.org/ABJNA

Table 2: Effect of egg size and strain on growth performance of cockerels (Starter phase)

\begin{tabular}{|c|c|c|c|c|c|}
\hline \multirow[b]{2}{*}{ Parameters } & \multicolumn{3}{|c|}{ Egg size } & \multicolumn{2}{|l|}{ Strain } \\
\hline & Small & Medium & Large & Dominant Black Yaffa Brown & \\
\hline Av. Initial weight (g) & $33.95 \pm 0.59^{b}$ & $36.70 \pm 1.21^{b}$ & $41.94 \pm 0.89^{a}$ & $38.26 \pm 1.39$ & $37.13 \pm 1.49$ \\
\hline Av. Final weight $(\mathrm{g})$ & $517.68 \pm 11.79^{b}$ & $591.31 \pm 16.54^{a}$ & $610.19 \pm 14.45^{\mathrm{a}}$ & $575.98 \pm 18.44$ & $570.13 \pm 17.75$ \\
\hline Av. Weight gain (g/day) & $8.64 \pm 0.21^{\mathrm{b}}$ & $9.91 \pm 0.28^{\mathrm{a}}$ & $10.14 \pm 0.25^{\mathrm{a}}$ & $9.60 \pm 0.31$ & $9.52 \pm 0.30$ \\
\hline Feed Efficiency & $0.19 \pm 0.01$ & $0.21 \pm 0.01$ & $0.21 \pm 0.01$ & $0.20 \pm 0.01$ & $0.20 \pm 0.01$ \\
\hline Av. Protein intake $(\mathrm{g})$ & $8.60 \pm 0.16$ & $8.93 \pm 0.13$ & $9.16 \pm 0.31$ & $8.95 \pm 0.17$ & $8.84 \pm 0.20$ \\
\hline Protein Efficiency Ratio & $2.64+1.65$ & $1.11 \pm 0.04$ & $1.12+0.06$ & $1.08+0.04$ & $2.17 \pm 1.09$ \\
\hline Mortality (\%) & $11.80 \pm 2.71$ & $4.63 \pm 3.01$ & $4.85 \pm 3.37$ & $6.30 \pm 2.04$ & $7.88 \pm 3.17$ \\
\hline
\end{tabular}

Table 3: Effect of interaction between egg size and strain on growth performance of cockerels (Starter phase)

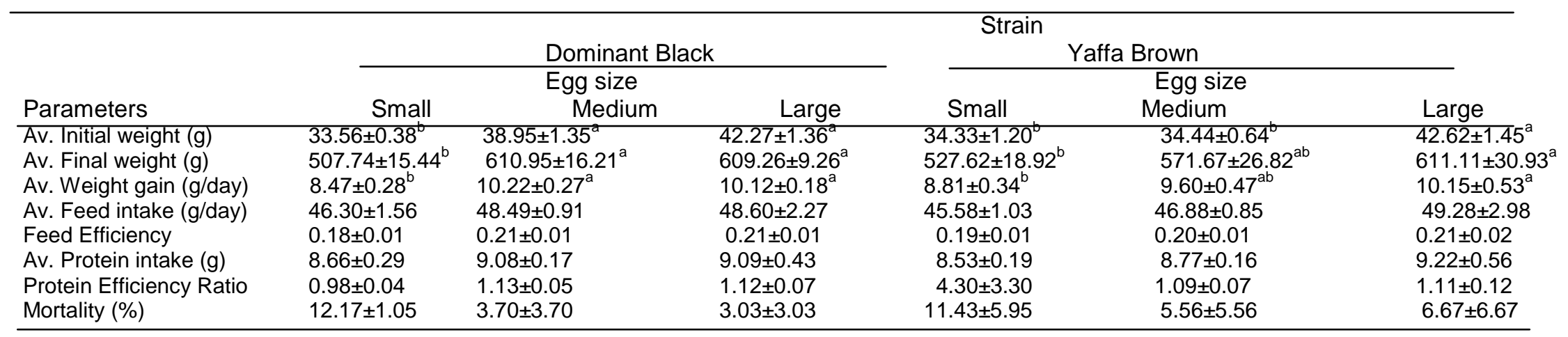

a,b means in the same row with different superscripts differ significantly $(P<0.05)$ 
AGRICULTURE AND BIOLOGY JOURNAL OF NORTH AMERICA

ISSN Print: 2151-7517, ISSN Online: 2151-7525, doi:10.5251/abjna.2011.2.12.1445.1453

(C) 2011, ScienceHuß, http://www.scihub.org/ABJNA

Table 4: Effect of egg size and strain on growth performance of cockerels (Growing phase)

\begin{tabular}{|c|c|c|c|c|c|}
\hline \multirow[b]{2}{*}{ Parameters } & \multicolumn{3}{|c|}{ Egg size } & \multicolumn{2}{|c|}{ Strain } \\
\hline & Small & Medium Lé & $\begin{array}{ll}\operatorname{arge} & \text { Do }\end{array}$ & Iant Black & Yaffa Brown \\
\hline Av. Initial weight (g) & $517.68 \pm 11.79^{\circ}$ & $591.31 \pm 16.54^{a}$ & $605.56 \pm 14.45^{a}$ & $575.98 \pm 18.44$ & $570.13 \pm 17.75$ \\
\hline Av. Final weight (g) & $1242.91 \pm 87.85$ & $1287.49 \pm 94.67$ & $1338.33 \pm 39.00$ & $1350.09 \pm 34.95$ & $1229.07 \pm 76.34$ \\
\hline Av. Weight gain (g/day) & $12.95 \pm 1.61$ & $12.43 \pm 1.44$ & $13.00 \pm 0.65$ & $13.82 \pm 0.60$ & $11.77 \pm 1.23$ \\
\hline Av. Feed intake (g/day) & $91.64 \pm 2.52^{\mathrm{a}}$ & $88.19 \pm 0.98^{\mathrm{ab}}$ & $82.72 \pm 2.69^{b}$ & $89.03 \pm 2.85$ & $86.25 \pm 0.74$ \\
\hline Feed Efficiency & $0.14 \pm 0.02$ & $0.14 \pm 0.02$ & $0.16 \pm 0.01$ & $0.15 \pm 0.01$ & $0.14 \pm 0.01$ \\
\hline Av. Protein intake $(\mathrm{g})$ & $13.83 \pm 0.38^{\mathrm{a}}$ & $13.31 \pm 0.15^{\mathrm{ab}}$ & $12.48 \pm 0.41^{b}$ & $13.44 \pm 0.43$ & $13.01 \pm 0.11$ \\
\hline Protein Efficiency Ratio & $0.94 \pm 10.28$ & $0.93 \pm 0.25$ & $1.04 \pm 0.07$ & $1.03 \pm 0.05$ & $0.91 \pm 0.10$ \\
\hline Mortality (\%) & $2.38 \pm 2.38$ & $1.67 \pm 1.67$ & $2.38 \pm 2.38$ & $4.28 \pm 2.18$ & $0.00 \pm 0.00$ \\
\hline
\end{tabular}

Table 5: Effect of interaction between egg size and strain on growth performance of cockerels (growing phase)

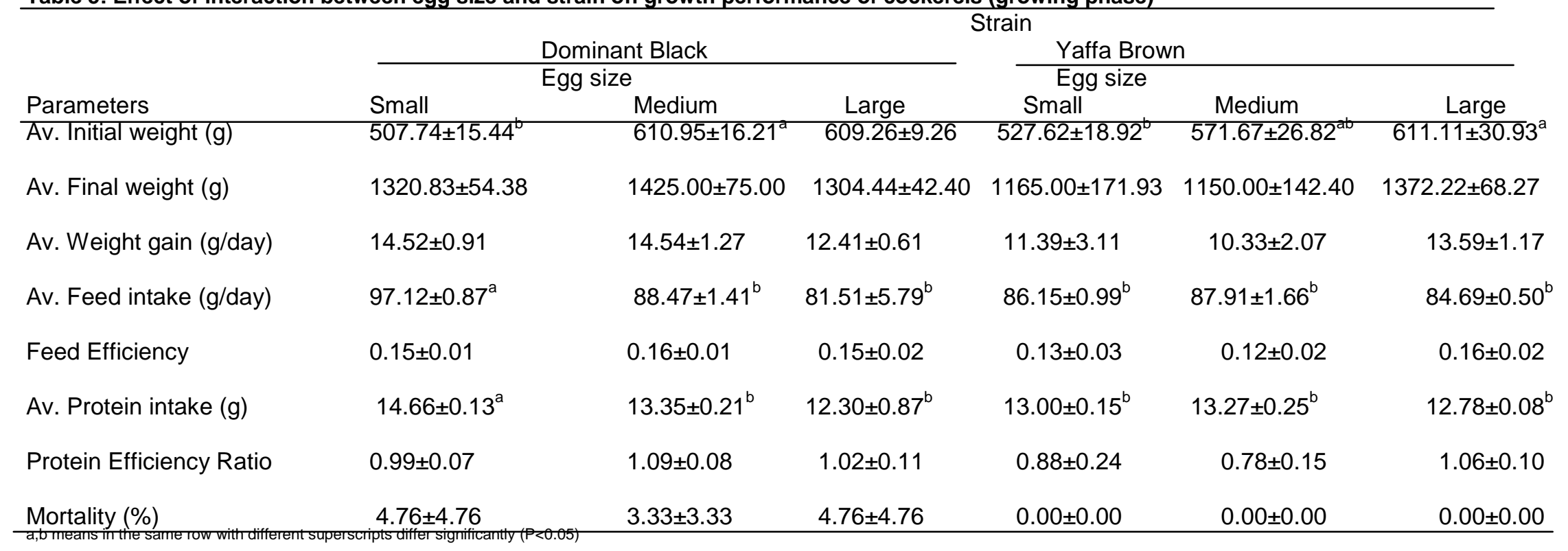


Agric. Biol. J. N. Am., 2011, 2(12): 1445-1453

Table 6: Effect of Egg size and Strain on carcass Characteristics of Cockerels

\begin{tabular}{|c|c|c|c|c|c|}
\hline \multirow[b]{2}{*}{ Parameters } & \multicolumn{2}{|c|}{ Egg size } & \multirow[b]{2}{*}{ Large } & \multicolumn{2}{|c|}{ Strain } \\
\hline & Small & Medium & & Dominant Black & Yaffa Brown \\
\hline Live weight (g) & $1191.67 \pm 63.91$ & $1229.17 \pm 70.83$ & $1235.83 \pm 49.81$ & $1265.56 \pm 36.29$ & $1172.22 \pm 58.89$ \\
\hline Hot dressed weight (g) & $944.90 \pm 91.48$ & $1046.02 \pm 70.83$ & $1037.49 \pm 51.96$ & $1076.88 \pm 32.57$ & $942.06 \pm 69.61$ \\
\hline Eviscerated weight (g) & $714.90 \pm 46.26$ & $732.29 \pm 44.80$ & $728.73 \pm 46.02$ & $765.05 \pm 27.52$ & $685.57 \pm 42.03$ \\
\hline \multicolumn{6}{|l|}{ Organs $^{1}$} \\
\hline Liver & $2.06 \pm 0.07$ & $1.92 \pm 0.08$ & $1.91 \pm 0.66$ & $1.93 \pm 0.04$ & $2.00 \pm 0.07$ \\
\hline Lungs & $0.60 \pm 0.02^{b}$ & $0.69 \pm 0.04^{\mathrm{a}}$ & $0.64 \pm 0.03^{b}$ & $0.60 \pm 0.02^{b}$ & $0.69 \pm 0.03^{\mathrm{a}}$ \\
\hline Heart & $0.47 \pm 0.02$ & $0.37 \pm 0.03$ & $0.46 \pm 0.02$ & $0.46 \pm 0.01$ & $0.47 \pm 0.02$ \\
\hline Kidney & $0.16 \pm 0.01$ & $0.16 \pm 0.01$ & $0.15 \pm 0.01$ & $0.15 \pm 0.01$ & $0.16 \pm 0.01$ \\
\hline \multirow{2}{*}{\multicolumn{6}{|c|}{ Cut-up parts ${ }^{2}$}} \\
\hline & & & & & \\
\hline Neck & $4.32 \pm 0.23$ & $4.41 \pm 0.14$ & $4.72 \pm 0.20$ & $4.58 \pm 0.14$ & $4.39 \pm 0.17$ \\
\hline Head & $3.72 \pm 0.14$ & $3.57 \pm 0.14$ & $3.55 \pm 0.08$ & $3.40 \pm 0.06^{b}$ & $3.83 \pm 0.10^{\mathrm{a}}$ \\
\hline Wings & $8.94 \pm 0.16$ & $8.77 \pm 0.21$ & $8.38 \pm 0.23$ & $8.87 \pm 0.15$ & $8.52 \pm 0.19$ \\
\hline Thighs & $9.32 \pm 0.27$ & $9.49 \pm 0.17$ & $9.31 \pm 0.35$ & $9.48 \pm 0.18$ & $9.27 \pm 0.25$ \\
\hline Drumsticks & $9.81 \pm 0.25$ & $9.49 \pm 0.18$ & $9.20 \pm 0.33$ & $9.66 \pm 0.22$ & $9.33 \pm 0.21$ \\
\hline Shanks & $4.87 \pm 0.15$ & $4.78 \pm 0.18$ & $4.75 \pm 0.17$ & $4.87 \pm 4.58$ & $4.73 \pm 4.39$ \\
\hline \multicolumn{6}{|l|}{ Muscle $^{3}$} \\
\hline Breast & $9.50 \pm 0.41$ & $9.58 \pm 0.23$ & $9.12 \pm 0.50$ & $9.65 \pm 0.28$ & $9.15 \pm 0.35$ \\
\hline Leg & $7.12 \pm 0.46$ & $6.55 \pm 0.19$ & $6.43 \pm 0.32$ & $6.71 \pm 0.13$ & $6.69 \pm 0.38$ \\
\hline Total & $32.74 \pm 0.96$ & $34.27 \pm 1.30$ & $32.88 \pm 1.53$ & $33.49 \pm 0.85$ & $33.11 \pm 1.21$ \\
\hline Bone & $17.53 \pm 0.64^{\mathrm{a}}$ & $17.33 \pm 0.43^{\mathrm{ab}}$ & $15.86 \pm 0.46^{b}$ & $17.03 \pm 0.55$ & $16.78 \pm 0.34$ \\
\hline Meat : Bone & $1.89 \pm 0.08$ & $1.99 \pm 0.08$ & $2.08 \pm 0.09$ & $2.00 \pm 0.08$ & $1.97 \pm 0.06$ \\
\hline \multicolumn{6}{|l|}{ Offals } \\
\hline Small intestine weight (\%) & $2.83 \pm 0.30$ & $2.46 \pm 0.17$ & $2.69 \pm 0.05$ & $2.51 \pm 0.16$ & $2.82 \pm 0.23$ \\
\hline Small intestine length (cm) & $150.23 \pm 5.64^{b}$ & $150.06 \pm 5.39^{b}$ & $70.95 \pm 7.55^{\mathrm{a}}$ & $154.44 \pm 5.24$ & $159.72 \pm 5.82$ \\
\hline Large intestine weight (\%) & $0.30 \pm 0.04$ & $0.23 \pm 0.03$ & $0.32 \pm 0.06$ & $0.32 \pm 0.04$ & $0.25 \pm 0.03$ \\
\hline Large intestine length (cm) & $10.78 \pm 0.27$ & $10.37 \pm 0.77$ & $10.31 \pm 0.33$ & $0.44 \pm 0.39$ & $10.54 \pm 0.43$ \\
\hline Caecal weight (\%) & $0.39 \pm 0.03$ & $0.35 \pm 0.02$ & $0.44 \pm 0.05$ & $0.36 \pm 0.04$ & $0.42 \pm 0.02$ \\
\hline Caecal length (cm) & $16.17 \pm 2.00$ & $16.22 \pm 0.43$ & $18.82 \pm 0.58$ & $18.13 \pm 1.04$ & $16.01 \pm 0.96$ \\
\hline
\end{tabular}

a,b means with different superscript along the same row is signiticantly different $(P<0.05$

$1,2,3$ percentage of live weight 
Table 7: Effect of interaction between Egg Size and Strain on carcass Characteristics of Cockerels

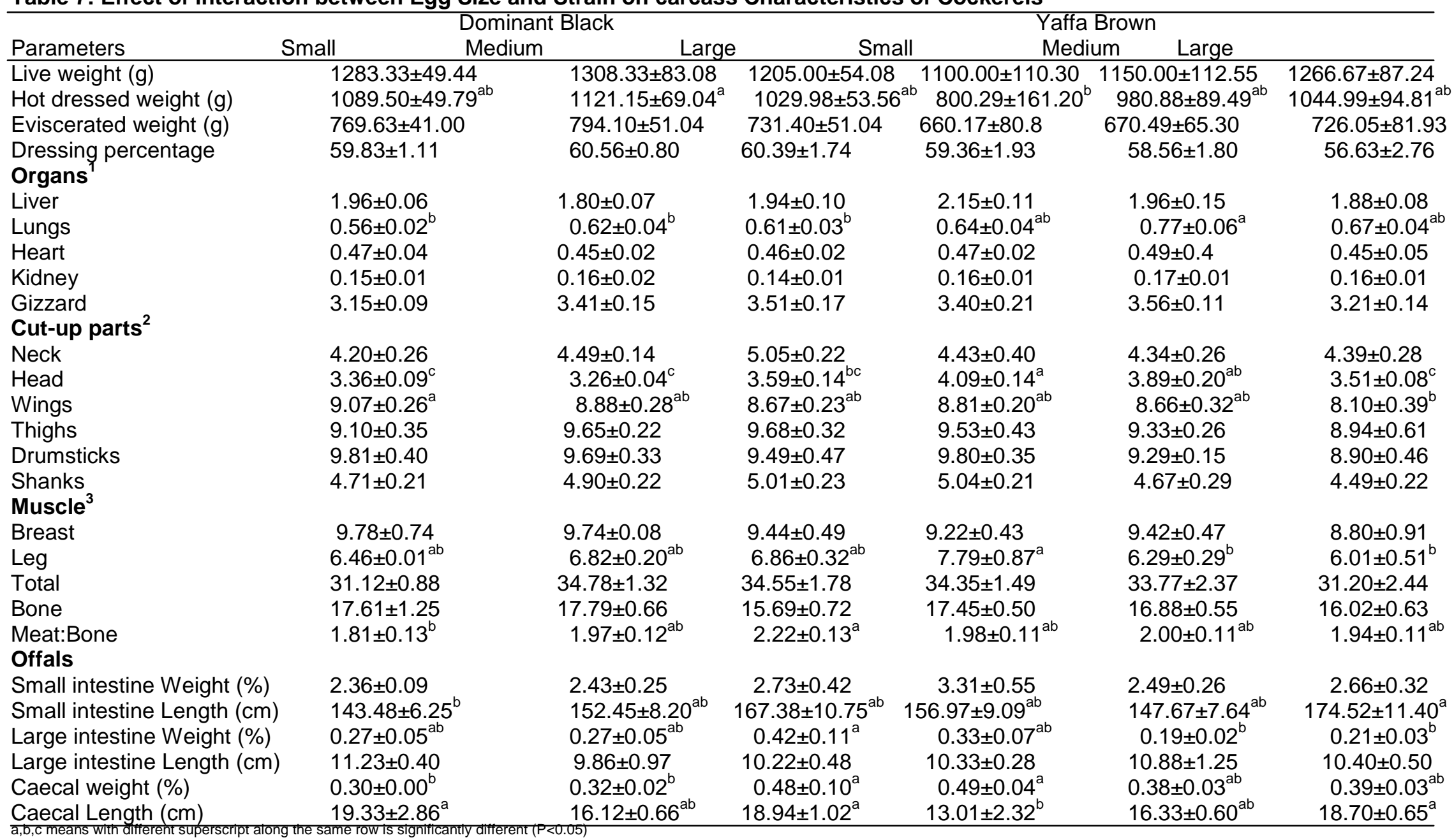

$1,2,3$ percentage of live weight 


\section{DISCUSSION}

The average live weight of cockerels was heaviest in the large-sized eggs than the other groups throughout the chicks phase and this confirmed the significance of big size-egg for incubation (Abiola et al., 2008). Tufft and Jensen (1991) studied the effect of egg weight on broiler chick performance and reported that as hen age and egg weight increased, body weight gain of the chicks increased but feed efficiency was not affected. This result corroborates the findings of Farooq et al. (2001) and Petek et al. (2003), and indicates that hatching egg weight, chick weight and chick growth are interrelated in quail. At growing phase, the birds from small and medium eggs were able to catch up with their counterpart at the end of growing phase. This could be attributed to the higher feed and protein intake ratio by the two groups as compared to the large eggs group. One of the factors affecting growth rate in birds is feed intake according to Ayanwale and Eyo (2007). The advantage of initially higher weight attributable to a larger egg diminishes rapidly after hatching while food intake is the main factor affecting final body weight (Wyatt et al., 1985). Though, the final weights of the cockerel at the end of the study were statistically similar, the highest weight obtained from cockerels from large egg may have resulted from the influence of hatching egg size and this is in agreement with the findings of Wilson (1991) who stated that the influence of egg weight remains until marketing when each gramme advantage at hatch translates into 2-13 g improvement in the body weight. The mortality throughout the rearing period was not significant $(P>0.05)$ though, the birds from small eggs had higher numerical value of mortality at starter phase. These results were similar to the findings of Singh et al. (2003) who reported that the egg size had no effect on mortality pattern in chicken while age of parent affected the mortality pattern. The increased demand for processed poultry products places considerable interest in composition and quality of the carcass. Carcass of high quality is in most cases regarded as one with a large amount of muscle and small amount of bone and fat (Obioha, 1992). The proportion of dressed weight to live weight determines the carcass quality. Though the dressing percentages of the cockerel birds were not influenced by the egg size at the end of the study, the numerical decrease in the value with increase in egg size could be linked to significant effect of bone composition in each group. It can be concluded from the result of this study that setting of medium and large egg sizes could only be beneficial if the target was to sell chicks of the two strains at the end of chick phase.

\section{REFERENCES}

Abiola, S. S., Meshioye, O. O., Oyerinde, B. O. and Bamgbose, M. A. (2008). Effect of egg size on hatchability of broiler chicks. Arch. Zootec. 57(217): 83-86.

Ayanwale, B. A. and Eyo, E. A. (2007). Performance characteristics of cockerels fed different commercial feeds. Agric. J. 2(6): 717-720.

Brah, G. S., Chaudhary, M. L. and Sandhu, J. S. (1999). Analysis of relation of egg weight with embryonic mortality, hatching time, chick weight and embryonic efficiency in chickens. Indian J. Poult. Sci. 34: 308 312.

Christensen, V. L. (2001). Development during the first seven days post-hatching. Pages $31-36$ in Perspectives in Fertilisation and Embryonic Development in Poultry. G. K. Baggott, M. R. Bakst, R. Bellairs, V. L. Christensen, G. M. Fasenfko, and J. M. Starck, ed. Ratite Conference Books, Oxford.

Deeming, D. C. (1995). What is chick quality? World's Poult. Sci. J. 11:20-23.

Farooq, M., Aneela, K., Durrani, F.R., Muqarrab, A.K., Chand, N. And Khurshid, A. (2001). Egg and shell weight, hatching and production performance of Japanese broiler quail. Sarhad J. Agric. 17: 289-293.

Gonzales, A., Satterlee, D. G., Moharer, F. and Cadd, G. G. (1999). Factors affecting ostrich egg hatchability. Poult. Sci. 78: 1257 - 1262.

Joubert, J. J., Potgieter, G. F., Noneyborne, N. S. and Cloete, A. (1981). the influence of egg size on the future development of broilers. Zootecnia International January, 24-25

Khurshid, A., Farooq, M., Durrani, F. R., Sarbiland, K. and Chand, N. (2003). Predicting egg weight, shell weight, shell thickness and hatching chick weight of Japanese quails using various egg traits as regressors. International J. Poult. Sci. 2(2): 164-167.

National Research council (1994). Nutrient requirements of poultry. $9^{\text {th }}$ rev. ed. National Academy Press,Washington, DC.

Obioha, F.C. (1992) A guide to poultry production in the tropics. 1st edition, pp $11-14$. Acena Publishers, Lagos, Nigeria.

Petek, M., Baspinar, H. and Ogan, M. (2003). Effects of egg weight and length of storage on hatchability and subsequent growth performance of quail. South African Journal of Animal Science 2003, 33 (4) 
Agric. Biol. J. N. Am., 2011, 2(12): 1445-1453

Pinchasov, Y. (1991). Relationship between the weight of hatching eggs and subsequent early performance of broiler chicks. Br. Poult. Sci. 32: 109-115.

SAS Institute, (1999). SAS User's Guide: Statistics. Inc., Cary, N.C., p.923.

Singh, B. P., Taparia, A. L., Tailor, S. P. and Jain, L. S. (2003). Factors affecting mortality pattern in chicken. Indian J. Poult. Sci. 38 (2):
Tufft, L. S. and Jensen, L. S. (1991). Effect of age of hen, egg weight and sex on chick performance and lipid retention. Poult. Sci. 70: 2411-2418.

Wilson, H. R. (1991). Interrelationship of egg size, chick size, post-hatching growth and hatchability. World's Poult. Sci. J. 47: 5-20.

Wyatt, C.L, W.D. Weaver Jr. and W.L. Beane. (1985). Influence of egg size, egg shell quality and post hatch holding time on broiler performance. Poultry Sci., 64: 2049-2055. 